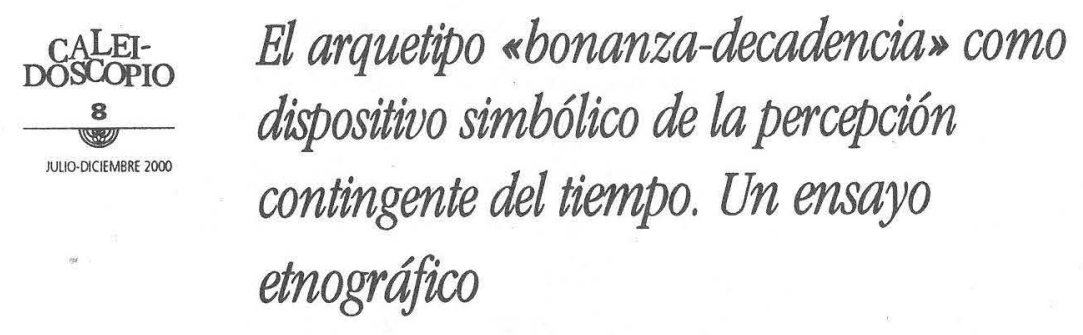

M. ALEJANDRO SIFUENTES S. Departamento de Teoría y Mélodos del Centro de Ciencias del Diseño $y$ de la Construcción/UAA

\title{
I. INTRODUCCIÓN
}

En este trabajo ${ }^{1}$ se recogen algunos elementos derivados del diario de campo elaborado en el transcurso del relato autobiográfico de un personaje de la pequeña ciudad de Loreto, al sur del estado de Zacatecas: Doña María López Medina, comerciante y ama de casa, residente en ese lugar por espacio de poco más de sesenta años y por tanto de los primeros fundadores de esa localidad. En rigor, se trata de un ensayo en el cual interpreto la manera en que este personaje percibe el tiempo y los cambios y permanencias que a lo largo de su dilatada vida ha experimentado, y de cómo su testimonio puede dictar o sugerir pistas para, a su vez, indagar la manera en que los habitantes originales de Loreto, y sus

1 El texto fue el producto de un ejercicio académico para la Maestría en Sociología de la Cultura de la Universidad Autónoma de Aguascalientes. El trabajo se realizó en el marco del Curso de Métodos Etnográficos, bajo la dirección del Dr. Alejandro González Villarruel y con la colaboración del Dr. Gustavo Marín, ambos del Centro de Investigaciones y Estudios Superiores en Antropología Social (CIESAS-México).

Las comillas (") se utilizan en el texto para indicar expresiones textuales del personaje. Los signos «», en cambio, para señalar expresiones del autor o de otras fuentes bibliográficas. 
descendientes, se relacionaron con su medio; por ello me interesaba conocer cómo, a partir de esta relación, los loretenses fundaron formas y estrategias de interacción social y simbólica que les permitieron afrontar y librar con éxito-integrándolos como parte del imaginario colectivo- los «embates» de la modernidad, rasgo singular que ha caracterizado a esta población que nació con las secuelas de la modernidad porfirista y que se consolidó con la modernidad instaurada a partir de la Revolución Mexicana.

Así, explícitamente, la etnografía perseguía los siguientes objetivos: a) recoger el relato y la memoria autobiográfica de Doña María López Medina, como ser humano y como cofundadora de la localidad de Loreto, Zac., a través de su propia historia de vida; b) describir e interpretar la percepción del tiempo, las permanencias y las transformaciones en la vida tanto de este personaje como, por inferencia, de Loreto mismo; c) explorar, por este medio, las posibles implicaciones del relato en orden a aportar elementos de explicación del proceso de cualificación simbólica de la relación tiempo / vida social / medio ambiente en poblaciones con características similares.

Me interesaba también rescatar del relato los descriptores e indicadores de aquella relación en varios niveles y dimensiones, a saber: vida cotidiana (dimensión praxeológica), visión del mundo, del tiempo y valores asumidos (dimensión axiológica), estrategias de sobrevivencia (dimensión económica), imaginario colectivo y sentido dado a los bienes de la modernidad (dimensión simbólica). Desde luego, era imposible abordarlos todos simultáneamente y con el mismo grado de profundidad, por lo que en el ensayo aparecen con mayor énfasis algunos indicadores en detrimento de otros no menos importantes, pero que por ahora serán puestos entre paréntesis hasta mejor ocasión. En suma, en el fondo del trabajo etnográfico subyacía una inquietud que no puedo ni debo soslayar: me interesaba explicar realidades más globales, digamos, reconstruir la memoria colectiva de los 
loretenses a partir de la memoria autobiográfica depositada en Mariquita.

\section{NOTA METODOLÓGICA}

La posibilidad de confiabilidad y generalización de los resultados presentaba de entrada dos obstáculos: una innegable relación de parentesco con el personaje $e^{2}$ y la singularidad misma del caso. Por principio de cuentas, la interacción con el personaje demandó una estrategia metodológica cualitativa. Por ello se utilizó una estrategia combinada consistente, por un lado, en el acopio de los datos de campo a través de la observación directa y una modalidad de la entrevista: la historia de vida o relato autobiográfico, realizándose la observación mientras la narración ocurría; en tanto que, por otro, con el propósito de reducir en lo posible los riesgos que para la investigación representaban aquellos obstáculos, se consideraron procedimientos apropiados cuyo sustento teórico y su modus operandi se discuten a continuación.

La polémica objetividad-subjetividad, en los acercamientos cualitativos, se ha desplazado desde quienes niegan validez o estatuto científico a todo trabajo basado en la preeminencia de los factores "subjetivos" de los sujetos, y de quienes apuestan a su total hipóstasis (que raya en excesos especulativos sin sustento empírico), hasta las posiciones actuales que reivindican la subjetividad como fuente rica de implicaciones útiles para la investigación y como fuente de gran potencial heurístico, sobre todo cuando el investigador coparticipa con sus sujetos en la construcción de su realidad. Por ello, los recientes trabajos ${ }^{3}$ en

2 Abuela materna del autor.

3 P. Banister et. al., Qualitative methods in psychology. A research guide, Open University, Philadelphia, 1994. M. Burton y C. Kagan, 
torno a esto no se han dejado tentar por el recurso fácil de evadir o ignorar olímpicamente la propia subjetividad del investigador y antes al contrario, la enfatizan como elemento que puede arrojar pistas a seguir o que puede contribuir a construir pautas explicativas a causa de la estratégica posición del investigador como parte de los sujetos estudiados. En este sentido, aquí se parte del supuesto de que objetivar la subjetividad no está reñido con la investigación científica, entendida en este ensayo como traducción de hechos en un lenguaje sociológico elaborado por el investigador o el etnógrafo a partir del reconocimiento de éste en los procesos y discursos estudiados, junto con los actores restantes. La implicación teórica de esto es pues, ni más ni menos, que la información se construye en la interacción de ambos, y por lo tanto los valores de neutralidad y objetividad cambian de contenido, pues los resultados constituyen productos negociados entre el investigador y los informantes. ${ }^{4}$ De hecho, los trabajos de estos autores han desarrollado y aplicado criterios de cientifici-

"Complementarism versus incommensurability in psychological research methodology", ponencia presentada en la British Psychological Society, History and Phylosophy Section Conference, York, 1997. Humberto Cavallin, "Evaluación psicosocial de viviendas multifamiliares de áreas reducidas/ Un estudio de caso", Tesis de Maestría, Facultad de Humanidades y Educación, Universidad Central de Venezuela, Caracas, 1997. N. Denzin e Y. Lincoln (eds.), Handbook of qualitative research, Sage, Thousand Oaks, 1994. Luis LaScalea, "La vivienda vista por sus usuarios", proyecto de investigación, Centro de Estudios del Espacio Arquitectónico, Facultad de Arquitectura y Urbanismo de la Universidad Central de Venezuela, Caracas, 1999. Y. Lincoln y L. Guba, Fourth generation evaluation, Sage, Newbury Park, 1985. H. Schwartz y J. Jacobs, Sociología cualitativa. Método para la reconstrucción de la realidad, Ed. Trillas, México, 1984. S. J. Taylor y R. Bogdan, Introducción a los métodos cualitativos de investigación, Paidós, Buenos Aires, 1986. Esther Weisenfeld, "La autoconstrucción, un estudio psicosocial del significado de la vivienda" Tesis Doctoral, Facultad de Humanidades y Educación, Universidad Central de Venezuela, Caracas, 1997.

4 Lincoln y Guba, op. cit. 
dad apropiados para los acercamientos cualitativos, sustituyendo los criterios de validez interna, validez externa y confiabilidad de las «ciencias duras» por otros equivalentes, tales como credibilidad, consistencia, confirmabilidad y transferibilidad. ${ }^{5}$

En el análisis del relato autobiográfico del personaje se utilizaron diversos procedimientos para derivar conclusiones, particularmente procedimientos de integración, cuyo propósito fue identificar patrones y temas constantes o repetitivos; de abstracción de elementos y relaciones, para subsumir elementos particulares en otros más generales; procedimientos para integrar comprensiones coherentes, a través de la construcción de coherencias conceptuales o teóricas que se ajustaran a las evidencias (y no viceversa); ${ }^{6}$ y procedimientos de triangulación, para validación de la información (preferentemente la saturación y la validez respondente o negociación). ${ }^{7}$

En el análisis, estos procedimientos se utilizaron en dos niveles básicos: A) en el más inmediato, es decir, aquél más directamente relacionado con el habla y el relato del personaje (patrones y temas constantes o repetitivos), se identificaron, extrajeron y categorizaron unidades lingüísticas o "declaraciones verbales"

5 De acuerdo con estos autores, por credibilidad se entiende que los datos de la investigación sean aceptables, es decir, creíbles, representando la contrapartida de la validez interna. Por consistencia se entiende la estabilidad de la información, que no se espera que sea absoluta. Por confirmabilidad se entiende la posibilidad de acuerdos entre los interobservadores y/o participantes de la investigación en la descripción de los fenómenos, dilucidación de los significados y generalización de las conclusiones, correspondiendo con la validez externa. Por transferibilidad se entiende la posibilidad de transferencia de situaciones similares al contexto y objeto estudiado para que, a través de la comparación, se extraiga lo específico y común al caso estudiado.

6 Felipe Martínez Rizo, El oficio del investigador educativo, Universidad Autónoma de Aguascalientes, México, 1989, 99. Pp. 154-158.

7 Denzin, citado en G. Pérez Serrano, Investigación cualitativa, retos e interrogantes, La Muralla, Madrid, 1994, pp. 82-84. 
en dos subniveles: a.1.) uno literal (stricto sensu), es decir, una primera emergencia del personaje a través de su oralidad, por la que era posible identificar palabras, frases o declaraciones que se repetían con alguna frecuencia ("la bonanza de...", la "casa", la "tienda", "el deber de...", "así tiene que ser", "se cambia uno según las necesidades", etc.); a.2.) uno amplio (lato sensu), o metafórico, por el cual las palabras remitían a un significado simbólico más profundo (el tiempo mítico mejor pero incierto, el refugio mítico, lo estable, lo inestable, lo esencial y lo contingente), y que fue el resultado de una primera inter-mediación entre el personaje y el etnógrafo. B) En un nivel mediato, que se descompone en varios subniveles: b.1.) una primera mediación del etnógrafo, esto es, aquélla en la que se abstrajeran elementos y relaciones particulares en otros más generales (lucha por sobrevivir en el lugar de origen - lucha por la vida, la relación bonanza-decadencia de las minas como expresión arquetípica de la incertidumbre, la casa como expresión de lo esencial, la tienda como manifestación de lo contingente); b.2.) una segunda mediación del etnógrafo, por la cual, a partir de las evidencias declaradas en el relato, se tejían argumentos coherentes concatenados, que en rigor constituyen el nivel más alto de interpretación (contrastar los apartados XI y XII). b.3.) Y por último, una segunda intermediación entre el personaje y el etnógrafo o entre éste y otros recursos, tales como la triangulación con documentación histórica o la confirmación de las evidencias declaradas con otros sujetos involucrados o con el investigador mismo cuando, como en este caso, se encuentra en un plano de filiación cercano al personaje o dentro del mismo grupo cultural.

Metodológicamente, se establece un ir y venir de cada una de estas fases y una cruza constante entre ellas aunque, cronológicamente, el primado del análisis le corresponda los incisos a.1.), a.2.), mientras que los incisos b.1.), b.2.) y b.3.) implican un trabajo posterior, del cual los dos últimos son casi simultáneos. El siguiente esquema podría representar el procedimiento: 


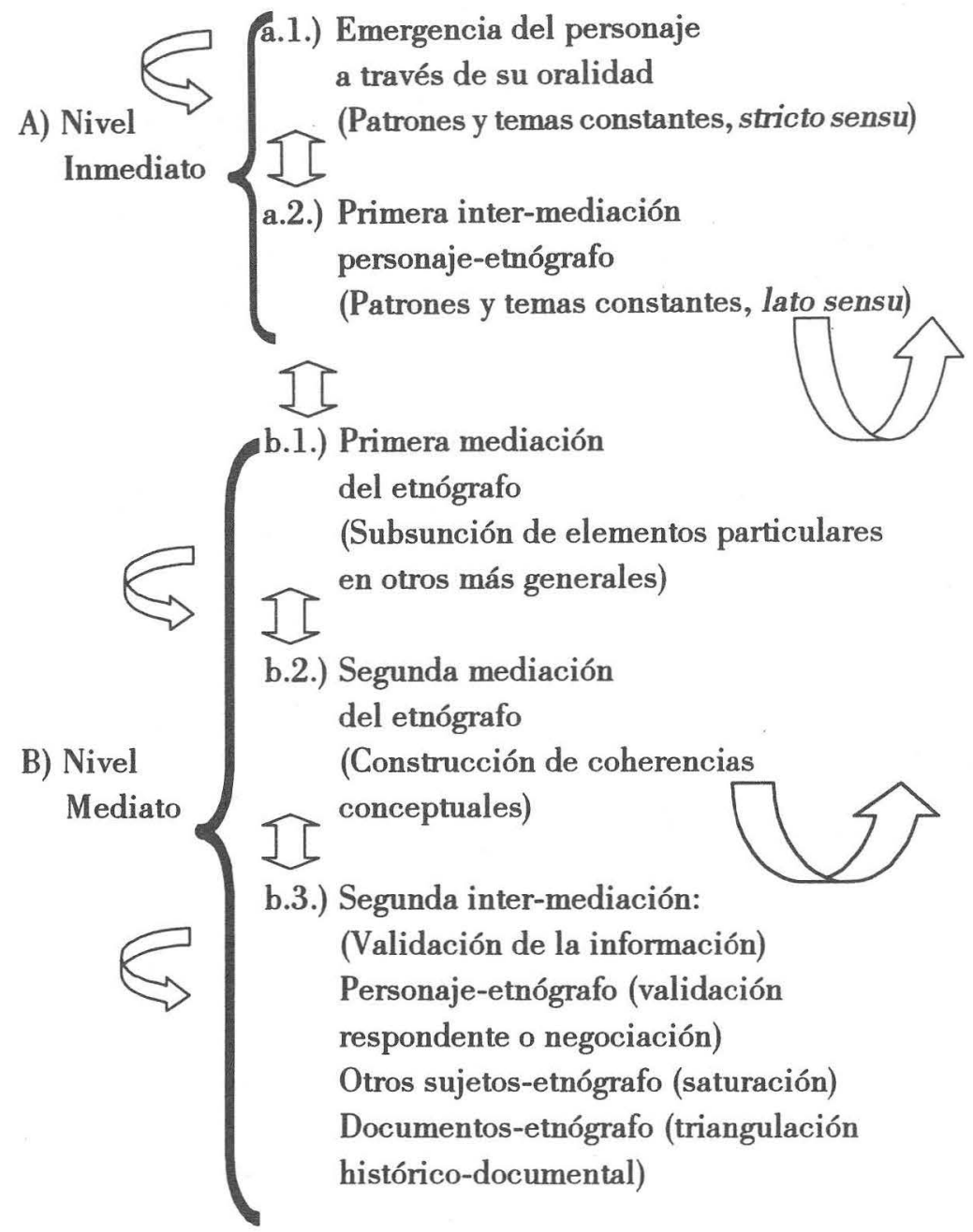

En este ensayo asumí el reto de la construcción intersubjetiva en la inteligencia de que más vale asumirla con conciencia que esquivarla por un prurito academicista no menos exento de riesgos. ¿Por qué no hacer etnografía desde dentro del mismo grupo cultural? Y como más vale pedir perdón que pedir permiso, procedo... 


\section{EL PERSONAJE}

Al momento del trabajo etnográfico, Doña María López Medina era una mujer de 91 años cumplidos, nacida en el año de 1905 y originaria del pueblo y mineral de Asientos, Aguascalientes; residente en la localidad de Loreto, Zacatecas, desde 1933, es decir, desde los 28 años, ella y su familia fueron de los primeros pobladores de esta comunidad, ya que llegaron tan sólo dos años después de su fundación oficial en 1931; casada y hoy viuda de Don Daniel Solís Campero, del pueblo de Dolores, municipio de Ojocaliente, Zacatecas, quien murió en el año de 1965. Madre de 8 hijos, cuatro hombres y cuatro mujeres, dos de las cuales murieron a temprana edad y dos varones más que fallecieron, ya adultos, en los años de 1977 y 1992. Tenía 15 nietos y dos bisnietos cuando comenzó a relatar su vida. Proviene de una familia longeva por el lado materno, dado que su madre vivió 93 años. Tuvo tres hermanos y cuatro hermanas, dos de ellas aún viven en la ciudad de Aguascalientes, a donde se trasladó parte de la descendencia. $\mathrm{Su}$ abuelo materno era criollo y fue administrador de una hacienda cercana a Asientos; su abuela materna era indígena.

Cuando estaba casada se dedicaba a las labores del hogar $y$, una vez viuda, al comercio en la tienda -dedicada a los giros de tlapalería, ferretería y papelería-, propiedad de su difunto esposo. Mariquita cultivó desde niña aficiones por la pintura, la lectura, las manualidades, la costura, el canto y la declamación; disciplinas que aprendió en la segunda de las dos escuelas particulares en las que estuvo en su natal Asientos, completando después su instrucción primaria -con una duración de seis años, desde ese entonces- en una "escuela del gobierno", de carácter laico, en la misma localidad. Sus familias paterna y materna, del mismo origen, vivían respectivamente de la elaboración y expendio de pan, y de la minería. Salió casada de Asientos en el año de 1925, 
durante cierto tiempo y vagó con su esposo hasta su establecimiento definitivo en Loreto, Zac., en donde nacieron sus seis últimos hijos. En sus «treinta», según su relato, admiró al Gral. Lázaro Cárdenas y a Benito Juárez; asimismo, guardó para sí una severa crítica a la iglesia jerárquica y calladamente, siendo católica convencida, cuestionó a los cristeros por su movimiento y en cierto modo justificó las medidas tomadas por Calles.

Mariquita, así llamada también por los lugareños, ha sido una persona conocida y estimada en Loreto gracias al comercio, lo mismo que al hecho de ser una de las habitantes más longevas de esta localidad y a la circunstancia de sus inclinaciones manuales y artísticas, entre las que destacan sus famosos nacimientos, que le valieron ganar concursos locales, y sus obras pictóricas, que ha presentado en exposiciones colectivas ahí mismo. Junto con su esposo, y gracias a lo que produjo su tienda «La Zacatecana», dio instrucción a todos sus hijos, siendo 5 de ellos maestros normalistas egresados respectivamente de las escuelas de Cañada Honda, Ags. (para mujeres), y de San Marcos, Zac. (para varones), quienes continuaron la tradición magisterial iniciada por la hermana menor de Mariquita, la maestra Carlota López Medina, quien estuvo tanto en San Marcos, cuando esta última era escuela mixta, como en Cañada.

Durante el relato, Mariquita estuvo postrada en cama debido a una enfermedad de tipo nervioso; su edad le ha impedido seguir al frente de su tienda, la que atendió incluso hasta el año de 1996. Y para su infortunio y desolación ha perdido, a lo largo de su vida, además de cuatro hijos; dos de sus más caros motivos de vivir: la tienda y su casa, la primera, la tuvo que rentar a un desconocido; la segunda, a uno de sus nietos recién casado.

Hoy, Mariquita sobrelleva su enfermedad en casa de su hija mayor, la maestra Ma. Socorro Solís López, en la ciudad de Aguascalientes, en donde entre dolores insoportables e intermitentes pasa su vida curándose, leyendo, pintando y rememorando su larga vida. 


\section{EL LUGAR DE LA ENTREVISTA}

La narración de la vida de Mariquita tuvo lugar en su habitación donde yacía enferma en la casa antes dicha. Es un espacio de aproximadamente $3.50 \mathrm{mts}$. de ancho por $5.50 \mathrm{mts}$. de largo y una altura cẻrcana a los $4.00 \mathrm{mts}$. Tiene un solo acceso y justo enfrente de él, en el lado opuesto, una ventana que da a la calle y que es el único vano de ventilación natural; la iluminación natural proviene de esta última y un poco también del cristal integrado a la misma puerta de entrada. La habitación tiene dos camas, un buró entre éstas, un closet de piso a techo y una consola cuya superficie superior es utilizada como especie de cómoda. Una lámpara de centro, con un foco de luz roja de bajo voltaje, da al espacio una atmósfera singular, de "habitación de enfermo», mientras un calentador eléctrico pugna por dar al cuarto un calor que no logran ni la atmósfera antedicha ni su orientación ligeramente desfavorable hacia el nororiente. Sobre el buró se halla una lámpara bajo cuya luz Mariquita dedica varias horas a la lectura, cuando los dolores le permiten gozarla; el buró se encuentra atestado de medicinas y todo el cuarto mismo presenta un desaliño que reproduce las condiciones de la habitación de la anciana en su casa de Loreto. Este es precisamente uno de los rasgos peculiares de Mariquita, y la experiencia nos ha dicho -a la familia, vaya-que a ella parece importarle un soberano cacahuate; ella lo ve con un desenfado indiferente que sólo resulta gracioso a quienes no tienen que limpiar el desorden. Intermitentemente, según lo permite su salud, Mariquita sale del cuarto y camina o hace quehacer en la casa; a veces sale a la calle a caminar y despabilarse ("desentullirse", dice ella).

El relato autobiográfico se realizó en estas condiciones, con la ayuda de una grabadora portátil.

\section{LA ENTREVISTA}

Las entrevistas para la grabación de las sesiones del relato autobiográfico tuvieron lugar entre el 15 y el 23 de enero de 1997, 
en su habitación de convaleciente de la casa de su hija mayor en la ciudad de Aguascalientes, durante las tardes. Fueron 5 sesiones, que produjeron un total de $4 \frac{1}{2}$ horas de cinta de audio y el equivalente aproximado a 76 cuartillas transcritas a espacio y medio con el tamaño de fuente 10. Puede ser cuestionable considerar el relato de Mariquita como una historia de vida; sin embargo, habida cuenta de las condiciones de salud de la enferma -que sorprendentemente no restaron ni brillantez ni claridad a su oralidad aunque, por el contrario, la edad de la anciana sí perturbó un poco su capacidad de rememorar-, no fue posible hacer más nada y por lo tanto consideré al relato como una historia de vida, porque llena, aunque sea mínimamente, las condiciones para serlo, a pesar de sus deficiencias técnicas. En todas las sesiones Mariquita se mostró muy colaboradora y entusiasmada ante la perspectiva de su propia autobiografía, aunque varias veces hubo necesidad de reactivar su memoria y estimular la manifestación de sus pensamientos profundos con preguntas directas (validación respondente o negociación), tanto de orden informativo e histórico, como moral, así como con la presentación previa de la guía de preguntas que elaboré para la ocasión, y que quiso revisar al efecto. Por lo general, salvo lo dicho anteriormente, Mariquita fue quien asumió el mando del relato, quedando claramente registrada en la grabación su fluida oralidad.

\section{El trabajo etNográfico}

Durante el relato se llevó un cuaderno de notas y al final de la jornada un diario de campo, en el que se recogió propiamente el trabajo etnográfico. El objeto del cuaderno de notas fue el de apuntar cualquier aspecto o pista que pudiera ayudar a la redacción del diario. Se hicieron observaciones tanto de lo que se relataba como de las circunstancias, condiciones y lugar en que se desarrollaba la narración. En el diario aparecen de un lado descripciones y observaciones, y del otro impresiones mías 
tratando de captar las regularidades del relato e interpretando con la jerga sociológica lo que iba observando, siendo apoyadas dichas observaciones y las constantes que iban emergiendo con citas textuales o ideas y sentimientos de la propia Mariquita (oralidad en sentido estricto).

Para fines de exposición, el siguiente apartado tiene la función de una «puesta en contexto» (triangulación histórico-documental), a efectos de que el lector comprenda el marco geográfico e histórico en el que la informante desarrolló su vida, y en el que cobra sentido la interpretación que más adelante se expone.

VII. El teRRITORIO

La región en la que se encuentran Asientos y Loreto corresponde a la vertiente nororiente del valle de Aguascalientes; el primero, se encuentra entre una serranía que se sitúa a más de 2 mil metros sobre el nivel del mar, famosa por los minerales que en un tiempo colocaron a Asientos en un grado de importancia económica comparable al de la villa de Aguascalientes; el segundo, se halla en un llano semidesértico -en donde insólitamente prospera la agricultura de riego- y es polvoso y frío en invierno. El mineral de Asientos data aproximadamente de 1770, aunque el lugar había sido poblado y colonizado en el siglo XVI por el Capitán Diego de Ibarra, uno de los fundadores de Zacatecas. Como tal, el mineral ha conocido diversas y más o menos exitosas bonanzas, efímeras muchas de ellas, seguidas de largas épocas de abatimiento de la producción, lo que ha ocasionado un relativo despoblamiento intermitente del sitio a lo largo de su historia. La economía del lugar depende por supuesto de la minería, aunque en los malos tiempos sobrevive de la agricultura. Una de las bonanzas más importantes ocurrió a finales del siglo XIX gracias a los oficios de Salomón Guggenheim - miembro de una de las familias de mayor fortuna de la época en México-, quien a través de sus empresas (entre ellas la American Smelting and Refining Company, 
ASARCO) monopolizó la extracción de metales en la zona, que luego eran transportados por ferrocarril a su enorme fundición urbana instalada en la ciudad de Aguascalientes, la Gran Fundición Central Mexicana, ${ }^{8}$ que, paradójicamente, de «mexicana» sólo tenía el nombre, puesto que era de capital extranjero. Después de eso, Asientos ha estado sumido por muchos años en un abandono que contrasta con la categoría que sus épocas de auge le dieron durante el siglo XVIII. Esa es la razón de la continua emigración de los lugareños hacia otros sitios cercanos -como Loreto o Aguascalientes-o bien hacia los Estados Unidos en el siglo presente. En diversas ocasiones se ha querido reactivar la producción minera sin lograrlo hasta el momento al mismo nivel que en los tiempos de auge.

VIII. LA LOCALIDAD

Loreto es actualmente una pequeña ciudad del estado de Zacatecas con una población de alrededor de 16,000 habitantes, cabecera del municipio del mismo nombre, cuya historia social, cultural y económica ha estado ligada a tres hechos fundamentales: el fraccionamiento de la Hacienda de San Marcos, el ferrocarril y la Escuela Normal Rural de San Marcos, Zacatecas.

Los antecedentes de Loreto se remontan a los primeros años del siglo XX. Se tiene noticia de que ya para fines del siglo pasado el ferrocarril pasaba por el valle loretense con rumbos opuestos hacia San Luis Potosí y hacia Aguascalientes; en el siglo XIX, la zona formaba parte de la Hacienda de San Marcos (en cuyo casco se instaló después la Normal del mismo nombre), propiedad de Don Genaro García Rojas - miembro de una familia de prosapia en la región-; todo hace suponer que este hecho le permitió a

8 Sobre la instalación y el desarrollo de esta empresa en el estado, ver Jesús Gómez Serrano, Aguascalientes: imperio de los Guggenheim, FCE, México, 1982. 
este personaje, a principios de la nueva centuria, colocar la producción de su propiedad rústica en los mercados regionales, antes de que la abandonara en 1911, a raíz del conflicto revolucionario. En 1914 se nombró un nuevo administrador de la hacienda y hacia 1918 se formó una agrupación de pequeños propietarios para solicitar tierras luego de que en agosto 20 de ese mismo año el gobierno del Gral. Enrique Estrada decretara la expropiación de los latifundios del Estado de Zacatecas. ${ }^{9}$ Así pues, Loreto estuvo ligado en su origen tanto a la estructura de la propiedad del régimen porfirista como a la de los regímenes revolucionarios (ejidos y, sobre todo, pequeña propiedad). De hecho, puede decirse que Loreto nació con la Revolución. En 1925 se levantó una pequeña construcción que fue conocida desde entonces como «Estación San Marcos», al centro del actual asentamiento, alrededor de la cual empezaron a reunirse viviendas -tanto efímeras como fijas-, y comercios, lo que comenzó por dar vida a lo que después sería esta población. Es así que en el año de 1931, luego de fallidos intentos por desmembrarse del Municipio de Villa García, los pequeños propietarios lograron que se oficializara por decreto presidencial la fundación de Loreto como cabecera municipal independiente, trasladándose finalmente los poderes del ayuntamiento desde su localización original en la comunidad de Bimbaletes, a una distancia de $3 \mathrm{~km}$ aproximadamente, a la nueva circunscripción hacia el año de 1935. Las primeras familias procedían de Asientos, de la ciudad de Aguascalientes y algunas de Encarnación de Díaz, Jal., mientras otras se habían movilizado a la nueva población desde los ranchos y pueblos comarcanos.

9 Puede verse una transcripción de los documentos relativos a la fundación de esta población en Maximiano Camarillo Neri y J. Guadalupe Camarillo García, Historia y Vida del Municipio de Loreto, Zac. 1931-1981, edición de los autores, Loreto, Zac., 1981. 
En 1933 se abrió la Escuela Normal de San Marcos, distante a tan sólo $4 \mathrm{kms}$. de Loreto, marcando así otro hito en la vida de los loretenses, dado que en los primeros años, las convicciones religiosas de algunas de sus gentes les impidieron aceptar una «escuela socialista» que, creían, habría de ejercer influencias perniciosas en el pueblo. Al cabo del tiempo, estas familias terminaron por aceptar y dar instrucción a sus hijos en esa escuela de tanto arraigo e influencia en toda la región. De este modo, la vida de Loreto quedó marcada también por el perfil de muchos de sus habitantes, forjados en una tradición magisterial (ligada a la educación socialista y a las misiones culturales) que implicó la internalización de una visión del mundo distinta a la de los pueblos tradicionales circunvecinos.

Loreto se convirtió, al cabo del tiempo y gracias al desarrollo de la pequeña propiedad, en un centro importante de producción y comercialización chilera, maicera, cebollera y tomatera. Asimismo, su localización en un valle plano y la infraestructura ferroviaria que lo marcó de origen permitió el florecimiento de un mercado regional, estableciéndose como un nudo comercial no sólo local sino a nivel de toda la comarca. Todo ello ocasionó la generación de excedentes que a su vez determinaron la formación de importantes fortunas, facilitando a los ricos y notables del pueblo -y a otros no tan ricos- costear los estudios profesionales de sus hijos, quienes emigraron a la ciudad de México a la «universidad» o al "poli». De tal suerte que todas estas circunstancias otorgaron a los habitantes de Loreto un cierto «status moderno», diferenciado del resto de las rancherías y pueblos de su alrededor. Ello facilitó la recepción y la apertura a otras comodidades, satisfactores, entretenimientos y formas e imágenes de la vida moderna de aquella época; por ejemplo: la estufa, el refrigerador, el teléfono, el cha-cha-chá y el rock and roll, el automóvil, la arquitectura moderna (a través de un templo muy singular), el radio, el cine, la televisión, y ahora las antenas parabólicas y los vídeo-cassettes. Entre estos satisfactores, en el 
imaginario colectivo loretense el cine ha asumido una importancia simbólica indisputable. Loreto fue y es conocido como un pueblo cinero, cuyos sueños de progreso podían ser imaginados y vistos a través de la pantalla y el celuloide; también, durante mucho tiempo, fue considerado como «bicicletero», por la abundancia de este tipo de transporte personal, sobre todo entre los habitantes de las rancherías circundantes. Igualmente debe ser señalado el sentido simbólico de las cantinas, una de las cuales («El Paraíso») forma ya parte de la historia de la vida disipada y de esparcimiento de los varones. Y no pueden soslayarse las famosas polvaredas que hacen de Loreto «el Paraíso Terregal», «Polvoreto» o «Lodoreto»-cuando acaso llueve-, en la jocosa expresión de los fuereños.

Recientemente, la región conoció cierto auge gracias al descubrimiento de nuevas y riquísimas vetas de mineral en el municipio contiguo de Noria de Ángeles, a causa de lo cual se estableció en Loreto una comunidad de técnicos canadienses y sus familias, dejando una derrama económica en las arcas municipales lo suficientemente buena como para emprender la dotación de algunos servicios urbanos (pavimentación, alumbrado público), antes ignorados por la paupérrima economía de los gobiernos zacatecanos, lo que dio cierto realce y sentido de progreso a la otrora seca e insípida imagen urbana loretense.

Hoy, nuevas colonias, fraccionamientos -incluso exclusivosy parques urbanos se han agregado al proceso de crecimiento y han hecho de Loreto una ciudad en pleno desarrollo.

Fue precisamente aquí en donde nuestro personaje pasó gran parte de su vida y en donde probablemente abonó la semilla de su sentido del tiempo, sembrada antes en su natal Asientos.

\section{El SENTido DEL TIEMPO}

La percepción del tiempo en las personas evidentemente depende de muchas circunstancias. Cuando se trata de individuos de avanzada 
edad, la cosa se puede complicar, o bien facilitar, según el estado físico o psicológico en el que éstas se encuentran. Las siguientes líneas fueron desarrolladas partiendo de un supuesto: la percepción del tiempo puede ser «medida» u observada en mejores condiciones cuando los sujetos se encuentran en estados liminales, digamos, en el caso de los ancianos, en situaciones en las que una enfermedad, la cercanía de la muerte o la idea del final de la vida catalizan las ideas y creencias sobre el paso del tiempo.

Este es el caso de Mariquita López Medina, quien, como se dijo, al momento del relato se encontraba postrada en cama debido a una enfermedad que aunque no ponía en riesgo su vida, sí la obligaba a plantearse la posibilidad de la muerte y, por lo tanto, esta situación la convertía en un sujeto apropiado para una exploración de este tipo. Por lo demás, ante la avanzada edad de Mariquita, se hacía necesario recoger su testimonio de su paso por la vida, dado que su relato podría ayudar a encontrar elementos para la explicación de la manera en que personas como ella conciben el tiempo y su relación con el mundo y su medio ambiente. Bajo esta lectura, y partiendo del trabajo etnográfico, trato de interpretar bajo que esquemas simbólicos percibe el tiempo nuestro personaje y cómo esos esquemas fueron utilizados como estrategias para relacionarse con otros congéneres y con su entorno físico cotidiano.

Antes de cualquier consideración profunda, y para facilitar la comprensión del problema, es necesario aclarar que en la vida de Mariquita existieron dos elementos rectores indiscutibles: su casa y su tienda. En torno a ambas giraba todo su universo simbólico y de relación social. En este ensayo pretendo explicar cómo funcionaron en su vida ambos aspectos, cuál es su relación con la idea del tiempo y qué dispositivos subyacen bajo tales bisagras vitales.

X. «Todo TIEMPO PASADO...» (PRIMER ACERCAMIENTO)

A partir del trabajo etnográfico, en el relato pude observar un primer nivel referido a la forma en que Mariquita concibe el 
tiempo: sería, digamos, el nivel más superficial y hasta cierto punto estereotipado; es decir, aquél en el cual el tiempo asume una dimensión nostálgica, en la línea de que «todo tiempo pasado fue mejor». En cierto modo es comprensible esta idea del tiempo y hasta natural en una anciana de la edad de ella. Pareciera ser que conforme avanza la edad de las personas se tiende a ubicar el pasado como un objeto irrecuperable y por tanto se selecciona algún pasaje o cadenas de hechos pretéritos felices, como representativos de la vida de los sujetos, excluyendo o subordinando los momentos de fracaso a las situaciones afortunadas, a menos que se haya pasado por situaciones límite o extremas en términos de desgracias más o menos dramáticas. Así se comprenden expresiones tales como "aquel tiempo era más bonito", o "la música de antes era más bonita", cuando Mariquita se refiere a su vida en su natal Asientos, cabecera del municipio del mismo nombre, perteneciente al estado de Aguascalientes. Desde luego, bajo estas expresiones podía detectarse una escala de valores que inevitablemente se asocian con el tiempo, dado que la instauración social de valores es un proceso necesariamente histórico. Pero este primer nivel, por ser demasiado -diría yoprosaico, no me permitía responder los cuestionamientos antes señalados, y por el contrario me lanzaba hacia terrenos que conducían inevitablemente a cierto empantanamiento teórico. Por lo menos, en el caso de Mariquita, aceptar que todo tiempo pasado fue mejor no le impedía ver con cierta indulgencia y tolerancia el presente. ¿Por qué?, ¿qué había detrás de esta actitud? Desde luego, no era desdeñable la idea de que con la edad ciertas personas ancianas se vuelven más sabias y tolerantes, aunque en este caso esta afirmación no me satisfacía por ser demasiado simplista. Conforme el relato avanzó, pude formular una hipótesis que poco a poco se fue configurando: la idea de una percepción contingente del tiempo como determinando cierta apertura tolerante al presente. Y esto ocurría, en el caso de Mariquita, de un modo muy particular y bastante peculiar, pero que me atrevo a 
suponer que puede señalar rasgos propios de un conglomerado social más amplio. A la interpretación de ese modo peculiar de concebir el tiempo están dedicados los siguientes párrafos.

\section{De la nostalgia a La instauración del arQ̨uetipo (SEGUNDO ACERCAMIENTO)}

Conforme el relato avanzaba, categorías tales como el valor de la vida en sí misma, la permanencia de lo esencial, la contingencia de lo inmediato, la inevitabilidad de la muerte y otras, iban tomando forma; por otro lado, me interesaba relacionar estas concepciones con el medio social y físico en el que nació, creció y desarrolló su existencia Mariquita, con la idea de encontrar regularidades que incluso pudieran ser compartidas por otros sujetos del mismo origen (subsunción de elementos particulares en otros más generales). La larga vida de Doña María me permitía suponer que su persona encarnaba múltiples experiencias y fuerzas generadoras de respuestas vitales.

Algunos aspectos llamaron mi atención. Mariquita manifestó cierta admiración por el Gral. Lázaro Cárdenas -a quien vio en Asientos y en Loreto- y por Benito Juárez y, lo más sorprendente, sus opiniones en torno al conflicto cristero fueron benevolentes para con Calles y bastante más desfavorables respecto a la iglesia jerárquica, a quien criticó, en el relato, debido a su opción histórica por los ricos; para Mariquita, el clero mandó como carne de cañón a los pobres rancheros mientras los instigadores curas permanecían escondidos en lugares como Asientos, en donde efectivamente se había ocultado un sacerdote. Por otra parte, cuando a partir del régimen de Cárdenas se implementó en todo el territorio nacional la «educación socialista», ésta fue bien acogida en el ánimo de Mariquita, como lo demuestra el hecho de que prácticamente todos sus hijos que llegaron a edad adulta estudiaron en las dos normales rurales de mayor influencia en la región: la de Cañada Honda y la "bolchevique" de San Marcos. Estos episodios, al margen del 
aspecto anecdótico, me indujeron a plantearme la cuestión del porqué una mujer con una formación católica podía aceptar sin problemas estos hechos no ahora, sino en el momento en que sucedieron. Es decir, no se trataba de la percepción benevolente de un hecho pretérito por esa visión tolerante y complaciente de la gente mayor hacia el pasado. Había más. Indudablemente algo debió haber influido la "escuela de gobierno" a la que asistió durante su niñez, pero esto no me satisfacía del todo porque para entonces, alrededor de 1915, la educación socialista no había sido adoptada y si acaso - en el mejor de los casos- no era más que una buena intención programática en el ideario revolucionario de algunos, muy pocos, personeros de la Revolución, cristalizando realmente hasta 1934. ¿Habría acaso influido en la formación de unos rudimentos de conciencia social el movimiento revolucionario de 1910? Era poco probable por la edad de Mariquita, aunque ella solía saltar de gusto cuando llegaban los revolucionarios a Asientos, quienes no le infundían el más mínimo temor, según su propio relato. Lo anterior demostraba que Mariquita profesaba una suerte de catolicismo tolerante a ideas socialistas, pero el punto esencial seguía en pie y sin respuesta: ¿jpor qué?; ¿tendría esto que ver con su idea del tiempo y de la vida?, ¿habría influido en ella el medio social y el medio ambiente en el que nació? El examen detenido del material etnográfico me permitió observar la emergencia una idea persistente que se repetía con cierta frecuencia y que me dio la pista para una explicación más plausible: me llamó la atención cierto patrón o esquema aparentemente muy introyectado en Mariquita, relacionado con la idea de "bonanza" y, yendo mucho más allá, con la idea de un esquema o patrón cíclico binario de bonanza-decadencia. Al parejo con esta idea, otra constante pudo ser deducida de la oralidad de la anciana: la idea del «deber de casar a los hijos», expresada como una responsabilidad ética y moral por la que todas las posesiones materiales se volvían un medio para un fin supremo, ante el cual el propio ser se desvanecía. «La tienda» de Mariquita, 
así, apareció en el relato como una de las bisagras en torno a la cual giraba el destino de toda la familia. Y no era una casualidad que fuera precisamente la tienda, dado que ésta conllevaba una carga simbólica asociada con lo efímero -con lo contingente, expresado por el comercio y su signo, el dinero que va y viene-, por contraposición a la carga simbólica de «la casa», asociada con lo permanente y dentro de ésta, la cocina, que eventualmente cambiaba de lugar, como expresión, de nueva cuenta, de lo contingente. ${ }^{10}$ Parecía como si esta idea de lo contingente dependiera de las bonanzas y las crisis de aquélla (la tienda), de sus altibajos, ante los cuales no tenía cabida la duda: había que luchar contra la adversidad para sacar a la familia adelante, para darles casa y casorio a los hijos, para infundirles seguridad y sentido de responsabilidad.

La casa y la tienda, de este modo, se fueron configurando como signos que expresaban los valores simbólicos de "estabilidad» (el regazo amoroso del refugio) e inestabilidad (la incierta lucha por la vida, que dependía de la inconsistencia del comercio). De ahí la imagen redundante o el esquema reiterativo de los ciclos de bonanza y crisis. Pero había más. Una circunstancia, imprevista y afortunada a la vez, me permitió «medir» el significado que para Mariquita tenía «La Zacatecana»: poco antes de la sesión de grabación efectuada en enero 20, Doña María tuvo que recibir a una persona con quien iba a pactar el contrato de arrendamiento de la tienda; el hecho me permitió corroborar que la propiedad tenía un valor tanto simbólico como económico, por cuanto alrededor de ella giró por mucho tiempo no sólo la vida de Mariquita, sino de toda la familia Solís López.

El hecho de que en el relato aparecieron continuas referencias y alusiones a los ciclos de apogeo-decadencia (la "bonanza de

10 Debo esta observación sobre el carácter también contingente de la cocina, a Marco Marcello Montes Skertchly, estudiante de la Maestría en Diseño Arquitectónico de la U.A.A. 
Tampico", la "bonanza de Asientos", la "bonanza de Loreto" mismo) me sugirió la existencia de un arquetipo primigenio aún más profundo, que remitía a un esquema binario dicotómico básico, introyectado como símbolo de la existencia misma en las gentes de Asientos, quienes, en mi hipótesis, lo habrían traspolado a otro fin de mundo como Loreto, donde las condiciones físicas del medio no eran mejores. Es decir, el haber nacido y crecido en una tierra como Asientos, un mineral cuya historia estuvo siempre determinada precisamente por los ciclos de apogeodecadencia, una tierra librada eternamente a su suerte por las bonanzas mineras, habría condicionado una percepción o sentido contingente del tiempo, por el que la vida era y fue todo el tiempo una incierta lucha por la sobrevivencia, un continuo apremio vital; así, la bonanza representaba simbólicamente la fuente de vida, mientras la decadencia era la fuente de no-vida (la muerte), que a su vez asumía simbólicamente el rol de catalizador que infundía la fortaleza de espíritu y la reciedumbre necesarias para enfrentar los infortunios de la naturaleza. Pues bien, Mariquita fue un producto de estas condiciones. Este esquema simbólico, introyectado en lo más hondo del ser, al parecer fue reproducido en Loreto por el personaje (debe recordarse que una buena parte de las familias fundadoras de Loreto provenía precisamente de Asientos), primero en compañía y luego en ausencia de Don Daniel Solís, su esposo, y sobre todo con mayor razón a la muerte de éste. Así, Loreto era simbólicamente Asientos; el hecho de que la casa fuera edificada con las propias manos de Don Daniel Solís, aumentó en. la familia el sentido de identidad, el sentido de pertenencia, una suerte de «yo soy de aquí», creencia incoada con una carga estructural asociada a los conceptos de arraigo y estabilidad. La casa, aunque "malita, fea y humilde", era su casa, el refugio mítico, su claustro existencial, era simbólicamente la casa de Asientos. El comercio, por el contrario, le permitía abrirse al mundo; la tienda estaba «en el siglo», fuera del claustro, era el dínamo que le permitía luchar por el sustento, era la oportunidad 
de vivir mejor: la tienda era Loreto, la casa era Asientos, como Loreto mismo era Asientos. "Uno se cambia -decía Mariquitasegún las necesidades", ya fuera en la casa, ya en la región; "yo hacía cocina donde encontraba", parece ser una expresión cuyo fondo puede interpretarse como «se establece uno donde hay mejor oportunidad». Y así fue como definitivamente Doña María se estableció en Loreto junto con su esposo y hasta con parte de su familia (su madre y algunas de sus hermanas), no sin antes «probar suerte» (una expresión bastante común en los reales de minas) en otros lugares cercanos, evidenciando con ello el carácter transitorio de la existencia en esta comarca, definido - como digopor la imagen del arquetipo de origen.

XII. HaCia UNA INTERPRETACIÓN CONCLUSIVA: El SENTIDO CONTINGENTE DEL TIEMPO

El relato autobiográfico de Mariquita me permitió concluir que su sentido del tiempo aparecía dominado por la idea de la «contingencia». La recurrente referencia a un pasado mejor, cuasi mítico, en el que Asientos aparecía a su vez como arquetipo del ciclo vital bonanza-decadencia (vida-muerte), operaba como un dispositivo simbólico en la vía de la construcción de estrategias de sobrevivencia para enfrentar lo imponderable. Ese esquema inmanente, casi ineluctable, actuaba como acicate para la acción y como proveedor de una fortaleza espiritual para superar la adversidad; de ahí la necesidad de la emigración.

Esa conciencia de lo contingente produjo su efecto: cierta «permisividad» tolerante a los cambios, cierta apertura a la novedad (como real de minas, los habitantes de Asientos estaban acostumbrados a la novedad: la aparición intermitente de extranjeros de toda índole y nacionalidad), si bien, en contraste, pervivía en Mariquita una suerte de sujeción a «lo esencial». Los elementos aparentemente contradictorios sólo son oposiciones sintagmáticas de un mismo eje paradigmático: la oscilación entre 
la idea del destino como algo ineluctable ("será que así tiene que ser") y como algo que el individuo modela a placer ("cada uno es el arquitecto de su propio destino"), no es sino la expresión polar de una unidad indisoluble de «lo esencial» y "lo contingente», de lo que permanece y lo que cambia como manifestación de lo primigenio: el ser.

El arquetipo se reproducía en Loreto: como un todo, Loreto era Asientos, la tienda era lo contingente («el dinero va y viene»), la casa lo esencial ("lo más esencial es ser ama de casa"). Todo ello explica en parte la relativa apertura de Mariquita-y de gentes como ella, del mismo origen- para aceptar o tolerar -y hasta fomentar en cierto modo- costumbres e ideas extrañas como la «educación socialista», la crítica a la iglesia jerárquica, la crítica a los cristeros, la admiración por Cárdenas, Benito Juárez y los bienes de la modemidad propios de la primera mitad de siglo $\mathrm{XX}$.

El esquema simbólico binario de bonanza-decadencia impelía, en Mariquita, a la percepción contingente del tiempo y a la construcción de estrategias seculares vitales.

\section{ComentaRio FINAL (DISGUSión Y PERSPECTIVAS)}

Al parecer, la credibilidad no se ve afectada por la circunstancia de mi propia pertenencia al mismo grupo filial del personaje o por el hecho de contaminar los resultados con mi propia subjetividad; por el contrario, el conocimiento directo de las condiciones en que se desenvolvieron las gentes de Loreto y mi familia materna (yo mismo viví ocho años en mi tierra natal, San Marcos), y el hecho de observar al mismo tiempo con distancia crítica y criterios razonados acontecimientos del pasado inmediato, me otorgaron una posición estratégica que me daba ventajas diferenciales para explicar una realidad específica -la de Mariquita- y, eventualmente, realidades más generales de los habitantes de Loreto; el problema más delicado radica en la 
confirmabilidad y en la transferibilidad, en suma, la generalización de la interpretación a realidades más globales.

Evidentemente, la interpretación aquí expuesta es válida para el personaje pero muy sugerente como forma de marcar posibles rutas cuyos resultados finales sean susceptibles de generalización. En este sentido, las perspectivas del trabajo etnográfico aparecen como promisorias ante el hecho de contar con estos otros criterios de cientificidad, no necesariamente homologables a los criterios de las «ciencias duras». En el caso que nos ocupa, la «percepción contingente del tiempo" como determinada por arquetipos y dispositivos simbólicos de la relación de las personas con su medio ambiente y su grupo cultural, requeriría la cruza de varias historias de vida de otros tantos personajes que vivieron condiciones semejantes o contrarias a las de Mariquita; demandaría, asimismo, otras estrategias de acercamiento cualitativo a los sujetos, más elementos de prueba y triangulaciones varias para pronunciarse por una explicación o por una interpretación con cierto grado de generalidad, al menos válida para los habitantes de Loreto. La puerta, pues, sigue abierta... 중 
$$
\text { - }
$$ 